\title{
PROTÓTIPO DE BIODIGESTOR: INSERÇÃO DA TEMÁTICA AMBIENTAL NA ESCOLA
}

\author{
Marcia Regina do N. de Souza ${ }^{1}$
}

\section{Antonio Carlos de Miranda ${ }^{2}$}

RESUMO: Na busca por uma sociedade sustentável, acreditamos que a Educação Ambiental crítica pode gerar a aliança entre natureza e o ser humano, sendo a escola um espaço privilegiado para formar cidadãos comprometidos com o desenvolvimento sustentável. A necessidade de empregar o protótipo de um biodigestor na escola surge do contexto de promover o conhecimento holístico do ambiente e incentivar a comunidade escolar a ser protagonista das ações destinadas a promover a sustentabilidade local. $O$ protótipo do biodigestor apresentado é de fácil montagem e baixo custo, e se adapta a pequenos espaços, sendo ideal para a sala de aula, e pode ser utilizado em todos os anos de escolaridade. A pesquisa teve como objetivos: construir um protótipo de biodigestor para ser usado na escola com a proposta de divulgação científica, propor para a escola discussão sobre contribuição das matrizes energéticas no cenário socioambiental e promover a inserção da Educação Ambiental crítica e transformadora na prática pedagógica.

Palavras-chave: Biodigestor, sustentabilidade, escola.

\footnotetext{
${ }^{1}$ Mestre em Educação Ambiental; Professora da Prefeitura Municipal de Duque de Caxias. $<$ marcia.bio11@gmail.com>

${ }^{2}$ Dr (UNICAMP); Professor do Programa de Pós Graduação Stricto Sensu (UNIPLI). <mirantam@ig.com.br>
} 


\section{INTRODUÇÃO}

Não é coincidência que a temática "aquecimento global" passou a ser concebida como importante após o setor econômico apropriar-se desse tema, por entender que sem os serviços ambientais há desabastecimento de energia e matéria prima que são essenciais para o funcionamento do sistema capitalista. É fundamental a percepção crítica que a busca por fontes alternativas de energias não deve atender somente a imposição ideológica do capitalismo, mas conceber o equilíbrio numa produção sustentável e humana, que só será possível com um novo paradigma de sustentabilidade, que também não seja produto da ideologia do capital, senão haverá apenas transferência do uso da energia fóssil para outras fontes, que exploradas sem controle perpetuarão com a destruição do ambiente. É reconhecido pela maioria dos pesquisadores que as atividades humanas alteram o clima de forma decisiva. Para Vasconcelos \& Tamoio (2010), o envolvimento da sociedade e a transformação de modelos é vital para o enfrentamento das alterações climáticas, porém grande parte das políticas públicas propostas para esse enfrentamento não envolve a participação da sociedade.

Para Layrargues (2009), o Brasil é um dos países que tem no seu contexto histórico grande desigualdade e injustiça social, portanto a Educação Ambiental não deve se vincular somente com a Educação Ecológica, mas ser uma poderosa ferramenta de transformação da sociedade, desde que tenha um compromisso social. Nesse sentido, a expectativa da Educação Ambiental crítica é a transformação de valores, que inibam esse processo predatório instalado, principalmente após a Revolução Industrial. As questões que envolvem as fontes de energia ainda são debatidas de forma tímida nas escolas e na sociedade. Entretanto, essa temática está inserida de forma relevante no setor econômico, que cria um cenário de ilusão, geralmente, apresentando uma abordagem na qual a produção energética seria comprometida com a sustentabilidade.

A crise socioambiental que o mundo enfrenta está associada com o uso dos recursos naturais para atender a demanda dos meios de produção. Esse comportamento explica os danos ambientais que atingem o planeta nesse processo do acúmulo de riqueza. 
Neste contexto, uma alternativa energética a ser explorada com responsabilidade é o biogás, que é um gás combustível formado a partir da degradação anaeróbica de resíduos orgânicos, como o lixo doméstico, resíduos de atividades agrícolas e pecuárias, dejetos de animais e lodo da estação de tratamento de esgotos.

A geração de energia elétrica por meio da captação do biogás já existe no Brasil. Em 2004, foi inaugurada a usina termelétrica do aterro Bandeirante, em São Paulo, que foi a primeira a usar o gás metano $\left(\mathrm{CH}_{4}\right)$ para geração de energia no país, com capacidade de gerar $175 \mathrm{MW}$ por ano. A usina termelétrica do aterro São João, também em São Paulo, inaugurada em 2008, apresenta capacidade de gerar 200MW por ano, o que equivale ao consumo de uma cidade de 400 mil habitantes. A instalação da Usina do Biogás no aterro metropolitano de Jardim Gramacho, em Duque de Caxias (RJ), será explorada pela empresa Gás Verde e com toda estrutura em funcionamento, a usina irá capturar cerca de $200 \mathrm{~m}^{3}$ de biogás diariamente. A Petrobras tem contrato assinado para comprar o gás e usá-lo como fonte de energia na refinaria de Duque de Caxias (REDUC). A Usina do Jardim Gramacho será o maior projeto de redução de gases do efeito estufa e também a maior do mundo na categoria de aterros, com capacidade de obter US $\$ 10$ milhões em Certificados de Emissão Reduzida (CER), nos próximos quinze anos (COELHO, 2010).

Nogueira (1986) considera que tratar os resíduos orgânicos é a forma mais ecológica de reduzir a poluição da água dos rios, sendo os resíduos de origem humana e animal, as formas mais comuns de poluição desse ecossistema. Porém os resíduos industriais não podem ser desprezados, já que podem apresentar carga poluidora muito alta, nesse sentido a biodigestão anaeróbia é um dos métodos para o tratamento dos resíduos poluidores de origem orgânica.

$\mathrm{O}$ metano $\left(\mathrm{CH}_{4}\right)$ é um gás com potencial de contribuição 21 vezes maior que o gás Carbônico $\left(\mathrm{CO}_{2}\right)$ para o aquecimento global (MAGALHÃES et al., 2010), e é o maior componente do biogás. Fontes naturais e antropogênicas produzem metano e uma parcela significativa da presença desse gás na atmosfera é proveniente de resíduos 
orgânicos depositados no ambiente. Portanto, através de tratamento apropriado desses resíduos é possível aproveitar o metano com fins energéticos ${ }^{3}$.

Outra forma de captação do biogás é através das instalações de biodigestores, seja no espaço rural ou, seja no urbano. É importante lembrar que a produção de resíduos que sejam compostos majoritariamente de matéria orgânica atende a especificação para o aproveitamento energético com uso de biodigestores. Para Arruda et al. (2002), a China com 7,2 milhões de biodigestores instalados até dezembro de 1979, produziu um quantitativo de energia de cinco vezes a energia gerada pela usina de Itaipu, ou seja, 48 milhões de toneladas de carvão, além disso, os resíduos da biodigestão anaeróbia são aplicados como fertilizantes.

O Brasil também tem experiências significativas com o uso dessa tecnologia, no entanto não são divulgados para a população os benefícios no uso dos biodigestores. $\mathrm{O}$ biogás e o biofertilizante produzidos no interior do biodigestor, através da biodigestão anaeróbia agregam valores culturais, ambientais e históricos.

A biodigestão anaeróbia representa alternativas para resolução de problemas ambientais, a demanda por produção energética sustentável, o tratamento dos esgotos e do lixo orgânico, aproveitamento de dejetos dos rebanhos, controle da poluição, preservação do sistema hídrico e a fertilidade do solo, são exemplos da relevância desse processo da natureza. Outro fato que precisa ser considerado é que os resíduos industriais, agrícolas e humanos possuem bactérias, vírus, fungos e vermes, que podem ser patogênicos. Se esses detritos forem despejados no ambiente, ocorre à contaminação e a propagação de doenças entre os seres vivos, e nesse aspecto o biodigestor pode auxiliar na demanda do serviço de saneamento básico (FARIA, 2011; VILLELA \& SILVEIRA, 2006; NOGUEIRA, 1986).

\footnotetext{
${ }^{3}$ Leite et al. (2004), ressaltam que o metano é um poderoso gás do aquecimento global, a redução da emissão desse gás para a atmosfera é passível de gerar créditos de carbono, de acordo com o (MDL) previsto no Protocolo de Quioto, o que gerar receitas para o empreendedor do aterro, receitas provenientes da venda de energia e de créditos de carbono gerados em aterros sanitários pode mudar a percepção que a sociedade tem dos aterros sanitários e consequentemente do lixo.
} 
Os efeitos das alterações climáticas decorrentes do aquecimento global e as leis que visam à proteção do ambiente têm valorizado o uso dos biodigestores. Que podem ser uma alternativa interessante do setor agropecuário. Nesse sentido, o uso dos biodigestores pode reduzir as áreas desmatadas para a produção biocombustíveis, manter o solo fértil, restringir o uso de agrotóxicos e fertilizantes, já que o Brasil ocupa o primeiro lugar nessa modalidade, limitar a utilização de medicamentos, como antibióticos, entre outros, nos rebanhos e na criação de aves, além de diminuir os resíduos orgânicos despejados no ambiente.

\section{MATERIAIS E MÉTODOS}

\subsection{PROTÓTIPO DE BIODIGESTOR.}

A problemática desta pesquisa surgiu a partir do interesse em desenvolver o protótipo do biodigestor de baixo custo, para ser aplicado como material didático em sala de aula. Tem como pressuposto que a escola não pode permanecer alheia aos conflitos socioambientais existentes, ela precisa ser um espaço que desperte no grupo questionamentos, entre outros, por exemplo, acerca das diversas possibilidades de matrizes energéticas, e suas contribuições positivas ou negativas para o ambiente. Por sua vez, o protótipo de um biodigestor se apresenta como um importante instrumento para trazer à tona essa discussão de forma interdisciplinar. Cabe lembrar ainda que são usados há muito tempo principalmente por culturas milenares, como a chinesa e a indiana, o que pode propiciar uma discussão histórica dessas civilizações. Portanto, a construção e o desenvolvimento de um protótipo de biodigestor, em sala de aula, torna o aprendizado mais significativo, despertando curiosidades e gerando conhecimentos, permitindo inserir o estudo da Educação Ambiental na sua vertente crítica.

A Educação Ambiental crítica é um instrumento essencial para o entendimento e o enfrentamento das relações de poder historicamente construídas e modeladas pela espécie humana, portanto, transformar uma sociedade baseada no domínio e destruição do ambiente, envolve profundas reflexões e ações dos atores inseridos nesse processo 
de mudança. Neste contexto, a escola surge como espaço democrático para que os sujeitos possam compartilhar suas reflexões acerca dos problemas socioambientais que interferem na vida do ser humano. É nessa linha de pensamento que Frazão, Silva \& Castro (2010) sinalizam que a Educação Ambiental deve tratar temas significativos para a escola e também para a comunidade em que está inserida.

Atento a essas questões, a investigação teve como cenário à Escola Municipal Coronel Eliseu no ano 2012, com 22 alunos, sujeitos da pesquisa, os quais foram divididos em dois grupos de 11, o primeiro grupo é constituído por alunos do $5^{\circ}$ ano de escolaridade, e o segundo grupo por alunos do 9ำ de escolaridade. A Unidade escolar fica localizada no segundo distrito de Duque de Caxias, num local de difícil acesso, sendo o bairro atendido por uma única linha de ônibus. A população do bairro ainda enfrenta problemas com os serviços de saneamento básico.

Em uma primeira etapa, antes de apresentar aos alunos, testamos vários modelos de protótipos e diversos tipos de carregamento. Nortearam essas tentativas, fundamentalmente, as seguintes características: baixo custo, fácil confecção e manuseio, que não represente perigo para os alunos e possa ser usado na sala de aula. Optou-se por material transparente, pois permite a observação do material orgânico e de fenômenos que ocorram durante o processo da biodigestão anaeróbia.

O modelo selecionado foi concebido com garrafas PET de $3 \mathrm{~L}$ e com os seguintes materiais: cola de silicone, fita adesiva larga, válvulas de aço de 3/4" e tubo de PVC de 3/4" com $29 \mathrm{~cm}$ e $50 \mathrm{~cm}$ conduite de 3/4". Foi abastecido com aproximadamente 1,5 $\mathrm{Kg}$ de biomassa (casca de abóbora, folhas de alface, arroz e pequenos pedaços de carne) e 1,3 litros de água (Figura 1). 


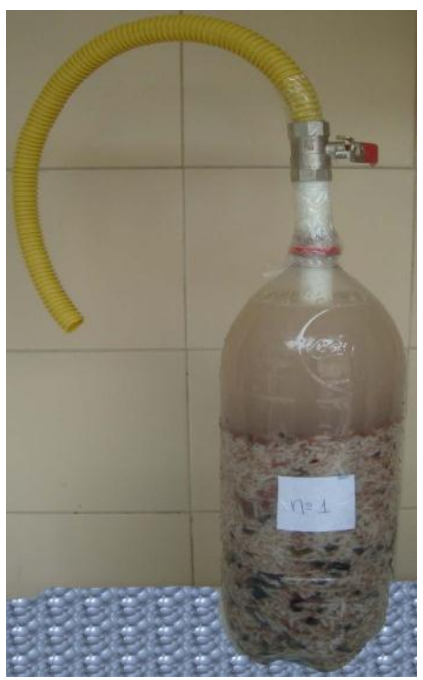

FIGURA 1: biodigestor em garrafa PET

\subsection{TESTE DA PRODUÇÃO DE BIOGÁS.}

O teste para verificar a produção de biogás nos protótipos de garrafa PET, foi baseado em um mecanismo de verificação da pressão do biogás dentro de um biodigestor. Junto ao biogás sempre existe vapor de água, que por condensação se deposita nos pontos mais baixo e, com o tempo, impedem a passagem do biogás. $A$ tubulação que conduz o biogás deve ter pontos mais baixos com dreno, que funciona como uma válvula de segurança. O dreno pode ser feito com uma conexão "T" do fundo da qual sai um pedaço de tubo, ou mangueira, que deve ser mergulhado em uma outra garrafa com água (Figura 2). O teste do protótipo do biodigestor foi realizado de acordo com os princípios propostos pelo Manual de Treinamento em Biogás (2006). O conduite que estava acoplado ao protótipo do biodigestor foi embutido dentro uma garrafa PET com de água, após abertura da válvula do protótipo, o gás borbulhou dentro da garrafa PET usada para teste, sugerindo a presença do biogás. 


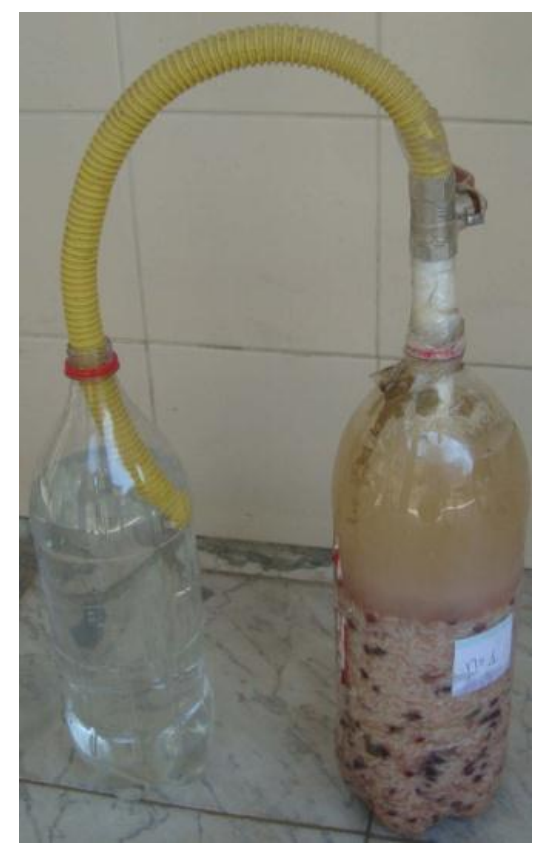

FIGURA 2: teste de produção de biogás.

\subsection{O PROTÓTIPO NA ESCOLA.}

A Sala de Leitura da Escola Municipal Coronel Eliseu foi o espaço utilizado para o desenvolvimento dessa atividade (montagem do biodigestor). Por sua vez, a escolha dos alunos seguiu um padrão arbitrário. Foram selecionados, como vimos, 11 alunos do 5ำ ano de escolaridade e 11 alunos do $9^{\circ}$ ano, os quais pertencem as turmas consideradas com defasagens de aprendizagem. A escolha apoiou-se na hipótese de que esses alunos têm pouco domínio sobre a temática ambiental, e que são influenciados, principalmente, pelos meios de comunicação (televisão) e através das aulas de Ciências e Geografia. Também foi relevante para essa escolha, a estrutura do Ensino Fundamental. $0^{\circ} 5^{\circ}$ ano de escolaridade é a última fase do primeiro segmento do Ensino Fundamental e as disciplinas são ministradas por apenas um professor. Já os alunos do 9ำ ano, tem um professor para cada disciplina e cursam o último ano do segundo segmento do Ensino Fundamental.

Os alunos receberam um questionário com cinco questões abertas, que foi aplicado na escola. O questionário tinha como objetivo identificar se era familiar para eles 
as seguintes palavras (conceitos): biodigestores, biofertilizantes, aquecimento global, sustentabilidade e biogás.

Identificamos dificuldade dos alunos do $5^{\circ}$ ano de escolaridade em responder às questões, pois apresentam ainda pouco domínio na leitura, na interpretação e na produção de texto. Sendo assim, para interpretar o discurso desses alunos foram realizadas entrevistas individuais, as quais permitiram conhecer as concepções desse grupo de alunos. Por exemplo, ao conceito de sustentabilidade, associavam 0 compromisso de sustentar a família: "Eu acho que é sustentação de uma família”. Já os alunos do 9a ano do segundo segmento, apresentaram também desconhecimento conceitual, mas responderam, por exemplo: "Já estudei isso, não sei explicar". "Não sei o que é, mas já ouvi na televisão".

Percebe-se nas respostas dos alunos do $5^{\circ}$ ano que apesar de não compreenderem o significado do conceito sustentabilidade, eles reconhecem a representação da palavra sustentar como um sentido positivo. Cabe lembrar que a Educação Ambiental fundamenta-se em promover a transformação dos sujeitos para enfrentar os problemas ambientais, essa transformação não ocorre sem a Leitura de Mundo, como defende Paulo Freire. Portanto, a partir dessa leitura a construção de conhecimentos passa a adquirir significado. Outra contribuição importante de Paulo Freire que cabe nessa análise seria utilizar, por exemplo, o método de alfabetização através de palavras geradoras para promover a leitura, a interpretação e produção de textos que poderiam ser desenvolvidas a partir da concepção dos alunos sobre o sentido da palavra sustentar ou de outros temas (termos) ambientais.

Após a análise do questionário foi realizado um segundo encontro com os alunos que participaram da pesquisa e discutiram-se os significados (conceitos) das palavras. Em um terceiro encontro discutiu-se a construção de um biodigestor, seu funcionamento e utilização. Apresentamos o protótipo do biodigestor para os alunos e um breve conteúdo sobre o biogás e suas possibilidades de uso. Em seguida, ocorreu um debate sobre a importância dos biodigestores para o tratamento dos resíduos orgânicos e o aproveitamento do biogás no aterro sanitário de Gramacho. Os dois temas escolhidos para o debate são relevantes e significativos devido aos problemas do esgoto a céu 
aberto e acúmulo de lixo ainda presente na comunidade, e o fato do aterro sanitário do Jardim Gramacho e a REDUC estarem instalados no município de Duque de Caxias, RJ.

Por fim, percebemos que a aplicação do protótipo do biodigestor poderá contribuir para transformar as práticas pedagógicas e inserir a Educação Ambiental crítica e dialógica, a partir do envolvimento da comunidade escolar na construção e execução de um projeto que apresente a possibilidade de discutir problemas significativos e estejam conectados com conhecimentos das diversas disciplinas do currículo escolar numa abordagem interdisciplinar. Ao mesmo tempo, foi possível através de um experimento despertar curiosidade e questionamentos de temas que envolvem questões econômicas, sociais e ambientais, que são essenciais para promover na escola a Educação Ambiental crítica, transformadora e com uma visão holística do ambiente. Por outro lado, permitiu a construção de um conhecimento novo para a comunidade escolar a cerca da importância da biodigestão anaeróbia na produção do biogás e biofertilizante. Além da percepção de que existem outras possibilidades de obtenção de energia que podem ser de fato sustentáveis. Há um grande potencial de possibilidades que possam promover o fortalecimento do grupo no enfrentamento das questões socioambientais e que poderão surgir com o desenvolvimento do projeto.

Em relação às respostas dos alunos, é importante ressaltar que para Vygotsky, a concepção de sujeito não se restringe somente ao biológico. A historicidade e cultura da humanidade, as relações sociais, o pensamento e a linguagem constituem o sujeito e este constitui outros sujeitos. Diferentes contextos apresentam diferentes sentidos para uma palavra (MOLON, 2009). Desse modo, o sentido que os alunos atribuíram para os termos desconhecidos foram construídos e apropriados nas relações sociais, através do pensamento e da linguagem

Considerando a relevância da constituição de um sujeito crítico, politizado e cidadão para a construção de uma sociedade mais igualitária, a Educação Ambiental precisa ganhar sentido na escola diante do momento de promoção da sustentabilidade da Terra. Não tem sentido construir o ser humano de conhecimentos compartimentados, sem a visão do todo, pois esse tipo de aprendizado contribui para o distanciamento do ambiente, construção e fortalecimento dos valores de individualismo e competição 


\section{CONSIDERAÇÕES FINAIS.}

A importância dessa pesquisa foi demonstrar que a partir do resgaste histórico do biodigestor é possível desenvolver a Educação Ambiental crítica na escola, pois a palavra biodigestor ganhou novo significado para o espaço da escola, não é de um objeto para gerar energia, mais um objeto de aproximação de novos conhecimentos vinculados com as relações sociais e históricas dos sujeitos a partir de uma prática pedagógica interdisciplinar. O protótipo do biodigestor surge como um experimento para questionamentos que não exigem respostas prontas, mas ganha significado com a participação da Educação Ambiental inserida nas disciplinas e no cotidiano das relações sociais que se estabelecem na escola Coronel Eliseu. A aplicação do questionário causou indagações sobre a ausência da interdisciplinaridade no processo ensino-aprendizagem, da importância de conhecer e entender sobre as mudanças das relações interfuncionais que conectam a memória a outras funções a partir dos conceitos de Vygotsky e finalmente o processo de apresentação do protótipo do biodigestor foi fundamental para divulgar um experimento científico capaz de despertar a curiosidade acerca de temas ambientais ausentes da escola e da sociedade. Os alunos se sentiram valorizados em fazer a proposta da construção de um projeto de Educação Ambiental para a escola, a possibilidade de toda comunidade escolar atuar na elaboração de um projeto, ganha significado de compartilhar saberes e habilidades, muitas vezes abafados na escola pela necessidade de atender a grade curricular.

\section{REFERÊNCIAS}

ARRUDA, M.H; AMARAL, L. P. PIRES, O. P. J \& BAFURI, C. R. V. Dimensionamento de biodigestor para a geração de energia alternativa. Revista Científica Eletrônica de Agronomia. 1(2), 2002.

COELHO, S.T Na rota dos resíduos. Revista Brasileira de Bioenergia. 4(9): 6-12, 2010. 
FARIA, R.L. A geração de energia pela biodigestão anaeróbia de efluentes: o caso da suinocultura.Instituto Superior de Engenharia, Arquitetura e desingn, CEUNSP, Salto, São Paulo, ano 2(3): 73-88, 2011. Disponível em www. Engenho info.

FRAZÃO, J. O; SILVA, J. M \& CASTRO, C. S.S. Percepção Ambiental de alunos e professores na preservação das tartarugas marinhas na Praia da Pipa- RN. Rev. Eletrônica Mestr. Educ. Ambient. ISSN 1517- 1256, v. 24, janeiro a julho de 2010.

FREIRE, Paulo. Educação como prática da liberdade. Ed. Paz e Terra, Rio de Janeiro, 2000. $150 p$.

LAYRARGUES, P.P. Repensar a educação ambiental: um olhar crítico. In: Educação Ambiental com Compromisso Social: O Desafio da Superação das Desigualdades, 11-32. São Paulo, Cortez, 2009.

LEITE, L.E.H.B.C; MAHLER, C.F; FILHO, L.F.B. Avaliação do potencial de receitas derivadas do biogás de aterros. 23를 Congresso Brasileiro de Engenharia Sanitária e Ambiental, 2004.

MAGALHÃES, G.H.C; ALVES, J.W.S; SANTOS FILHO, F; COSTA, R.M; KELSON, M. Redução de incertezas sobre o metano recuperado ( $r$ ) em inventários de emissões de gases de efeito estufa por tratamento de resíduos e sobre o parâmetro adjustment factor (AF) em projetos de coleta e distribuição de metano em aterros no âmbito do desenvolvimento limpo (MDL). São Paulo, Brasil, 2010. Disponível em www.cetesb.sp.gov.br. Acesso no dia 13/05/2012.

MANUAL DE TREINAMENTO EM BIODIGESTÃO, Winrock Internacional, Brasil. Versão 2.0, fevereiro de 2008. Organização: André de Paula e Moniz Oliver (Instituto Winrock Brasil).

MOLON, S.N. Repensar a educação ambiental: um olhar crítico. In: As contribuições de Vygotsky na formação de educadores, 141-170. São Paulo, Cortez, 2009

MORIN, E. \& KERN, A.B. Terra-Pátria. Tradução Armando Pereira da Silva, Lisboa: Instituto Piaget, 1993, p.137.

NOGUEIRA, L. A. H. Biodigestão: A alternativa energética. São Paulo, Nobel, 1986

VILLELA, I.A.C \& SILVEIRA, J.L. Biogás: Pesquisas e Projetos no Brasil/ CETESB, Secretária do meio Ambiente,In: Aspectos históricos e técnicos do uso do biogás produzido por biodigestores rurais,151-156.São Paulo: SMA, 2006. Disponível em; <http: //www.cetesp.sp.gov.br.>. 